\title{
Analisis Profil Pendidikan Tinggi Menurut Pilar Kebijakan: Kasus Provinsi Bali Tahun 2008/2009
}

\author{
Ida Kintamani Dewi Hermawan \\ Peneliti pada Pusat Statistik Pendidikan, e-mail: idakintamani@yahoo.com
}

\begin{abstract}
Abstrak: Tujuan analisis profil pendidikan tinggi di Provinsi Bali yaitu untuk memahami kondisi pendidikan tinggi di provinsi tersebut didasarkan pada dua pilar kebijakan pendidikan seperti tertuang dalam Rencana Strategi 2005-2009 dan kinerja program pendidikan tinggi. Hasil analisis menunjukkan bahwa pendidikan tinggi di Provinsi Bali menggunakan standar ideal masih belum merata dengan nilai capaian sebesar $54,59 \%$, masih belum bermutu dengan nilai capaian sebesar $43,92 \%$, dan kinerja pendidikan tinggi masih rendah dengan nilai capaian sebesar $49,25 \%$. Bila dibandingkan dengan standar nasional maka pemerataan pendidikan tinggi sebesar $80,51 \%$, mutu pendidikan tinggi sebesar $100,11 \%$ lebih besar daripada nasional, dan kinerja pendidikan tinggi telah mencapai 88,21\%. Dengan demikian, dapat disimpulkan bahwa bila pendidikan tinggi di provinsi Bali diarahkan ke standar ideal maka masih jauh dari harapan namun bila diarahkan ke standar nasional sudah cukup baik. Dengan kondisi seperti ini, disarankan agar pemerintah melakukan prioritas dalam pembangunan pendidikan tinggi di Provinsi Bali, yaitu mutu pendidikan harus dibenahi terlebih dahulu kemudian pemerataan pendidikan.
\end{abstract}

Kata kunci: analisis, profil pendidikan, pendidikan tinggi, pemerataan pendidikan, mutu pendidikan, dan kinerja program.

\begin{abstract}
The aim of analysis of Higher Education Profile in Bali province is to understand the condition of higher education in Bali province with assessed by two milestones of educational policy as enclosed in Strategic Planning 2005-2009 and performance of higher education program. The result of analysis based on ideal standard shows that higher education in Bali province is not yet equity with value of $54,59 \%$, not yet qualify with value of $43,92 \%$ and is still low performance of higher education with value of $49,25 \%$. If it it compared to national standard, equity in higher education is $80,51 \%$ and quality is $100,11 \%$ bigger than national standard and higher education performance is $88,21 \%$. The conclusion is higher education in Bali province evaluated using ideal standard is far away from hope but using national standard is very good. With this condition, it is suggested that government should give the priority to build higher education in Bali province, that is quality should be solved first then the equity of education.
\end{abstract}

Key words: analysis, education profile, higher education, equity of education, quality of education, and program performance

\section{Pendahuluan}

Indonesia adalah negara yang memiliki sumber daya alam yang melimpah namun belum cukup memiliki sumber daya manusia yang mampu mengelola potensi tadi menjadi sumber daya yang bisa membawa kemakmuran dan kesejahteraan bangsa. Hal ini juga menunjukkan bahwa Indonesia belum siap untuk menghadapi persaingan global. Di masa yang akan datang, pengembangan pendidikan tinggi tidak dapat dipisahkan dari perkembangan ilmu pengetahuan termasuk ilmu sosial, humaniora, teknologi, seni budaya, dan ekonomi dunia. (Departemen Pendidikan Nasional, 2004a: 9-11).

Strategi pendidikan tinggi dipengaruhi oleh kondisi internal lingkungan pendidikan dan kondisi eksternal pendidikan. Kondisi internal pendidikan dinyatakan dari angka partisipasi kasar (APK) PT dan APK PT Vokasi, persentase dosen berijazah S2/S3, sertifikasi dosen, jumlah paten yang berhasil diraih, publikasi internasional, dan prestasi mahasiswa Indonesia di ajang internasional melalui perolehan medali emas. Kondisi eksternal pendidikan dinyatakan dari sosial, budaya, dan 
lingkungan, ekonomi, teknologi, dan politik dan pertahanan, dan keamanan. (Kementerian Pendidikan Nasional, 2010: 7-16).

Berdasarkan pencapaian sasaran strategi dari tujuan strategis T4 ditunjukkan bahwa APK PT pada tahun 2009 sebesar 23,5\%, persentase prodi PT berakreditasi sebesar $69,6 \%$, persentase prodi PT berakreditasi minimal sebesar 44,4\%, 300 PT terbaik dunia versi THES sebesar 1 PT, 600 PT terbaik dunia versi THES sebesar 3PT, 200 PT terbaik Asia versi THES sebesar 8 PT, persentase dosen S-1 dan Diploma berkualifikasi S2 sebesar $57,8 \%$, persentase dosen S-2 berkualifikasi S3 sebesar $56,2 \%$, persentase dosen bersertifikat sebesar $15,4 \%$, persentase PTN bersertifikat ISO 9001:2008 sebesar 17\% dan PTS sebesar 10\%. (Kementerian Pendidikan Nasional, 2010: 32).

Kebijakan pengembangan pendidikan tinggi tidak dapat dilepaskan dari kebutuhan pembangunan di daerah. Adanya keterkaitan antara pendidikan tinggi dengan pemerintah daerah dapat dilihat dari dua sisi. Sisi pertama adalah pendidikan tinggi dapat berperan menunjang upaya pemerintah daerah dalam pengembangan di berbagai sektor pembangunan daerah seperti sektor ekonomi, sosial, dan budaya dengan memperhatikan prioritas kebutuhan dan potensi unggulan daerah yang bersangkutan. Sisi kedua adalah pemerintah daerah dapat berperan menunjang pengembangan pendidikan tinggi khususnya kegiatan perguruan tinggi di bidang penelitian dan pengabdian kepada masyarakat. Hal ini dapat terlaksana dengan upaya untuk mendorong kerja sama antara perguruan tinggi dengan pemerintah daerah. (Departemen Pendidikan Nasional, 2004b: viii).

Terkait dengan pencapaian sasaran strategi dan kebijakan pengembangan pendidikan maka Profil Pendidikan Tinggi dimaksudkan untuk memberikan gambaran yang menyeluruh tentang keadaan pendidikan tinggi di daerah yang bersangkutan pada suatu waktu. Gambaran menyeluruh tersebut diperlukan oleh berbagai pihak yang berkepentingan (stakeholders) untuk pembangunan pendidikan seperti Pemerintah Pusat, Gubernur, DPRD Provinsi, Ketua Bappeda Provinsi, Kepala Dinas Pendidikan Provinsi, kalangan industri, dan masyarakat. Mereka sangat memerlukan informasi lengkap mengenai pendi- dikan tinggi di suatu daerah atau di daerahnya untuk berbagai keperluan, antara lain dalam rangka pengembangan daerah, pengentasan kemiskinan, dan peningkatan kesejahteraan rakyat. Dialog antara Pemerintah dengan Kepala Dinas Pendidikan Provinsi atau Pemerintah Provinsi dan diskusi dengan sektor-sektor lain akan lebih berbobot apabila pihak Pemerintah atau Dinas Pendidikan Provinsi dapat menyajikan kemampuan analisis yang handal dan didukung oleh data dan informasi pendidikan tinggi yang aktual, relevan, dan dapat dipercaya.

Dalam rangka pembangunan pendidikan maka perlu dihasilkan data dan informasi yang terintegrasi antara data pendidikan dengan data nonpendidikan sehingga dapat digunakan untuk semua pihak yang berkepentingan dengan pendidikan tinggi. (Chamidi, 2006). Selain itu, pembangunan pendidikan disusun untuk mengetahui pencapaian pendidikan tinggi, masalah yang dihadapi sebagai bahan perencanaan yang menyangkut pemerataan pendidikan dan peningkatan mutu pendidikan. Setelah diketahui masalah tersebut, diharapkan dapat disusun bagaimana cara mengatasi masalah tersebut. Pencapaian pendidikan hendaknya juga dikaitkan dengan faktor eksternal sehingga dapat digunakan sebagai bahan masukan untuk pengambilan keputusan seperti penyusunan perencanaan pembangunan wilayah, perencanaan pembangunan pendidikan tinggi, penyusunan kebijakan operasional pendidikan tinggi, dan informasi bagi pihak yang memerlukan.

Walaupun setiap tahun data pendidikan tinggi telah dihasilkan namun belum ada profil pendidikan tinggi yang dipublikasikan dalam bentuk analisis. Belum adanya analisis untuk Pendidikan Tinggi di setiap provinsi ini banyak dipengaruhi beberapa hal, misalnya karena pengelola pendidikan di pusat maupun di provinsi belum memiliki program aplikasi untuk menghasilkan program pembangunan pendidikan beserta analisisnya dan baik pengelola pendidikan di pusat maupun di provinsi mempunyai tugas yang sangat padat sehingga mereka tidak dapat melakukan analisis terhadap data Pendidikan Tinggi. Dengan demikian, manfaat adanya data pendidikan tinggi tidak dapat secara maksimal diperoleh. Namun, untuk mengetahui keadaan pendidikan secara 
menyeluruh maka pendidikan tinggi dan analisisnya sangat berperan.

Dengan adanya permasalahan tersebut maka dirasa perlu untuk mendayagunakan data pendidikan tinggi yang ada dengan menyajikan dalam bentuk Profil Pendidikan Tinggi dan analisisnya sehingga dapat dimanfaatkan untuk melaksanakan perencanaan pendidikan tinggi di tingkat provinsi maupun di tingkat pusat.

Ada beberapa kondisi pada saat sekarang dan permasalahan yang dapat terjadi dalam melakukan pendayagunaan data pendidikan tinggi dalam bentuk Profil Pendidikan Tinggi dan analisisnya, yaitu: 1) Bagaimana keadaan data nonpendidikan di Provinsi Bali?; 2) Bagaimana kondisi pendidikan tinggi di Provinsi Bali; 3) Bagaimana pendayagunaan indikator pendidikan tinggi di Provinsi Bali yang dihasilkan; dan 4) Bagaimana kinerja pendidikan tinggi di Provinsi Bali?

Tujuan dilakukannya analisis ini adalah untuk mengetahui empat variabel, yaitu: 1) keadaan nonpendidikan Provinsi Bali; 2) keadaan pendidikan tinggi menurut jenis lembaga Provinsi Bali; 3) hasil indikator pendidikan tinggi Provinsi Bali; dan 4) kinerja pendidikan tinggi Provinsi Bali dalam rangka memberikan bahan penyusunan kebijakan dan perencanaan pendidikan tinggi di Provinsi Bali. Selain itu, analisis ini dapat digunakan sebagai model untuk melakukan analisis sebagai bahan penyusunan kebijakan dan perencanaan pendidikan tinggi pada daerah lainnya.

\section{Kajian Literatur}

Berdasarkan pada permasalahan dan tujuan di atas dalam analisis profil pendidikan tinggi Provinsi Bali maka perlu dipahami terlebih dahulu tentang apa yang dimaksud dengan: 1) analisis, 2) pendidikan tinggi, 3) profil pendidikan tinggi, 4) indikator pendidikan tinggi, dan 5) kinerja pendidikan tinggi.

\section{Analisis}

Berdasarkan Wikipedia, analisis dalam linguistik adalah kajian yang dilaksanakan terhadap sebuah bahasa guna meneliti struktur bahasa tersebut secara mendalam, sedangkan pada kegiatan laboratorium analisis berarti kegiatan yang dilakukan di laboratorium untuk memeriksa kandungan suatu zat dalam cuplikan. (http://id.wikipedia.org/ wiki/Analisis). Dengan demikian, dapat disimpul- kan bahwa analisis dalam pendidikan adalah kajian yang dilaksanakan terhadap pendidikan untuk meneliti tentang kandungan yang ada dalam pendidikan. Kandungan pendidikan tersebut dapat diartikan sebagai keberhasilan pendidikan di suatu daerah. (Ida Kintamani, 2009b).

Surat Keputusan Menteri Pendidikan dan Kebudayaan Nomor 0259/U/1977 tentang Kordinasi Pengolahan Data di Departemen Pendidikan dan Kebudayaan (Depdikbud) menjelaskan juga tentang analisis dalam beberapa kegiatan yang dilakukan untuk pengolahan data di Depdikbud. Analisis data didefinisikan sebagai suatu kegiatan untuk mempelajari dan meneliti data yang ada dan membuat interpretasi yang diperlukan. Dalam melaksanakan analisis terdapat tiga hal yang perlu diperhatikan, yaitu: 1) adanya data yang dianalisis baik dalam bentuk tabel, grafik atau bentuk lainnya; 2) adanya kegiatan untuk melakukan analisis data yaitu meneliti, memeriksa, mempelajari, dan membandingkan beberapa data yang ada; dan 3) adanya interpretasi dengan cara menarik simpulan secara deskriptif dari kegiatan meneliti, memeriksa, mempelajari, dan membandingkan beberapa data tersebut.

\section{Pendidikan Tinggi}

Undang-Undang Nomor 20, Tahun 2003 tentang Sistem Pendidikan Nasional Bagian Keempat, Pasal 19 menguraikan tentang pendidikan tinggi merupakan jenjang pendidikan setelah pendidikan menengah yang mencakup program pendidikan diploma, sarjana, magister, spesialis, dan doktor yang diselenggarakan oleh Perguruan Tinggi. Pendidikan tinggi diselenggarakan dengan sistem terbuka. Pada Pasal 20, ayat 1 dinyatakan bahwa perguruan tinggi dapat berbentuk akademi, politeknik, sekolah tinggi, institut, atau universitas. Pada ayat 3 dinyatakan bahwa perguruan tinggi dapat menyelenggarakan program akademik, profesi, dan/atau vokasi. (Departemen Pendidikan Nasional, 2003: 20).

\section{Profil Pendidikan Tinggi}

Profil pendidikan tinggi adalah gambaran yang menyeluruh tentang keadaan pendidikan tinggi di daerah yang bersangkutan pada suatu 
waktu, misalnya Profil Pendidikan Tinggi, Tahun 2008. Dalam perencanaan pembangunan di bidang pendidikan seperti perencanaan, di tingkat nasional atau provinsi diperlukan data dan informasi yang lengkap tidak hanya menyangkut data di bidang pendidikan melainkan juga data nonpendidikan. (Chamidi, 2006). Pada kenyataannya, untuk mendapatkan data dan informasi, khususnya data nonpendidikan sangat sulit. Hal itu disebabkan karena semua instansi memiliki data masing-masing dan belum ada satu instansi yang melakukan integrasi terhadap data tersebut. Agar diperoleh data yang terintegrasi, lengkap, dan mutakhir mengenai keadaan pendidikan maka perlu dikaitkan dengan data dan informasi nonpendidikan seperti administrasi pemerintah daerah, demografi, geografi, ekonomi, sosial budaya dan agama serta transportasi dan komunikasi. Selain itu, untuk mengatasi masalahmasalah pendidikan tidak hanya dapat dilakukan melalui faktor internal pendidikan melainkan juga harus dilihat faktor eksternal pendidikan. (Kementerian Pendidikan Nasional, 2010: 7-15).

Untuk mengatasi masalah di atas, Profil Pendidikan yang cukup komprehensif dapat dipandang sebagai bahan masukan yang cukup handal untuk penyusunan perencanaan pembangunan pendidikan yang realistis. Oleh karena itu, dengan menggunakan profil pendidikan tersebut dapat diketahui dan diperhitungkan berbagai faktor yang ada dalam suatu wilayah, termasuk faktor pendukung dan penghambat yang mempengaruhi perkembangan suatu wilayah dan khususnya perkembangan pendidikan.

Berdasarkan data dan informasi yang komprehensif yang termuat di dalam profil pendidikan tinggi dapat dilakukan analisis secara deskriptif untuk mengetahui pencapaian pendidikan tinggi. Dengan menggunakan pencapaian yang ada diharapkan dapat dilakukan identifikasi masalah terhadap tiga pilar kebijakan pendidikan. Berdasarkan masalah yang ada maka perlu dilakukan analisis untuk perencanaan dengan pendekatan berdasarkan data dan informasi yang ada sehingga dapat digunakan sebagai bahan pengambilan keputusan dan penentuan kebijakan. (Biro Perencanaan, 2002).

\section{Indikator Pendidikan Tinggi}

Rencana Strategi Depdiknas tahun 2005-2009 ditetapkan adanya tiga pilar kebijakan pembangunan pendidikan, yaitu: 1) pemerataan dan perluasan akses pendidikan; 2) peningkatan mutu, relevansi dan daya saing pendidikan; dan 3) penguatan tata kelola, akuntabilitas, dan citra publik pendidikan. Sesuai dengan Rencana Stategi Depdiknas maka indikator pendidikan yang ada dalam Profil Pendidikan Tinggi juga diarahkan pada tiga pilar kebijakan pembangunan pendidikan. (Departemen Pendidikan Nasional, 2007).

Pemerataan dan perluasan akses pendidikan tinggi dimaksudkan agar setiap orang mempunyai kesempatan yang sama untuk memperoleh pendidikan tinggi. Kesempatan memperoleh pendidikan tinggi ini tidak dibedakan antara jenis kelamin, status sosial ekonomi, agama, dan lokasi geografis. Berkaitan dengan kebijakan tersebut maka pemerintah berupaya memperluas akses pendidikan tinggi agar partisipasi lulusan sekolah menengah makin meningkat dan pada akhirnya mengarah pada pencapaian daya saing lulusan pendidikan tinggi secara global. (Mahdiansyah, 2008)

Untuk mengukur pemerataan dan perluasan akses pendidikan tinggi maka digunakan beberapa indikator kunci. Indikator kunci utama di tingkat nasional adalah APK. APK digunakan untuk program PAUD, tingkat SMP, SM, dan PT. (Departemen Pendidikan Nasional, 2006a dan Departemen Pendidikan Nasional, 2008). APK adalah perbandingan antara jumlah siswa pada jenjang pendidikan tertentu dengan jumlah penduduk kelompok usia sekolah yang sesuai dan dinyatakan dalam persentase (Departemen Pendidikan Nasional, 2002). Dengan demikian, APK PT adalah perbandingan antara jumlah mahasiswa dengan jumlah penduduk kelompok usia 19-24 tahun dan dikalikan dengan angka 100. Rumus yang digunakan adalah:

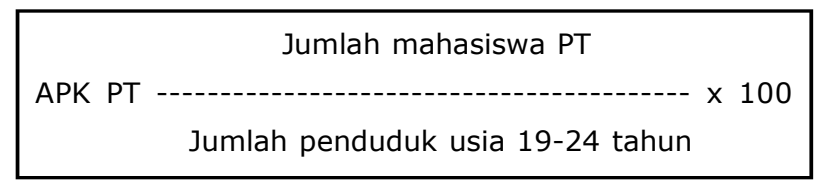

APK PT digunakan untuk melihat partisipasi penduduk yang bersekolah di PT. Makin tinggi nilai APK berarti makin banyak penduduk yang 
bersekolah. Sebaliknya, makin kecil nilai APK maka makin sedikit penduduk yang bersekolah

Selain indikator kunci yang digunakan di tingkat nasional maka terdapat indikator lain yang dapat digunakan untuk mengukur pemerataan dan perluasan akses pendidikan, yaitu 1) persentase mahasiswa menurut jenis kelamin (\% MJK), 2) rasio mahasiswa per lembaga (R-M/Lbg), 3) rasio mahasiswa per dosen (R-M/D), 4) persentase mahasiswa baru (\%MB), dan 5) animo ke APT (Biro Perencanaan, 2002).

Persentase MJK dihitung dari jumlah mahasiswa laki-laki dibagi dengan jumlah mahasiswa seluruhnya atau mahasiswa perempuan dibagi dengan jumlah mahasiswa seluruhnya dan dinyatakan dalam persentase. Rumus yang digunakan ada dua, yaitu:

1) \%MJKI adalah persentase mahasiswa laki-laki

\begin{tabular}{|l}
\hline J Mhs PT \\
Jumlah mahasiswa laki-laki PT \\
Jumlah mahasiswa selulruhnya PT
\end{tabular}

2) $\%$ MJKp adalah persentase mahasiswa perempuan

\begin{tabular}{|ll|}
\hline & Jumlah mahasiswa perempuan PT \\
$\%$ Mhs PT & $-0 .-100$ \\
& Jumlah mahasiswa seluruhnya PT \\
\hline
\end{tabular}

Persentase MJK digunakan untuk melihat seberapa banyak keseimbangan antara mahasiswa laki-laki dan perempuan yang bersekolah. Bila nilainya mendekati $50 \%$ berarti seimbang. (Pusat Statistik Pendidikan, 2008b).

R-M/Lbg dihitung dari pembagian antara mahasiswa PT dibagi dengan lembaga PT. Rumus yang digunakan adalah:

\begin{tabular}{c} 
Jumlah mahasiswa PT \\
R-M/Lbg PT $=$ Jumlah lembaga PT \\
\hline
\end{tabular}

Indikator R-M/LBg digunakan untuk melihat kepadatan mahasiswa di PT. Makin tinggi nilainya berarti makin padat, sebaliknya makin rendah nilainya berarti makin jarang.
R-M/D dihitung dari pembagian antara mahasiswa PT dibagi dengan dosen PT. Rumus yang digunakan adalah:

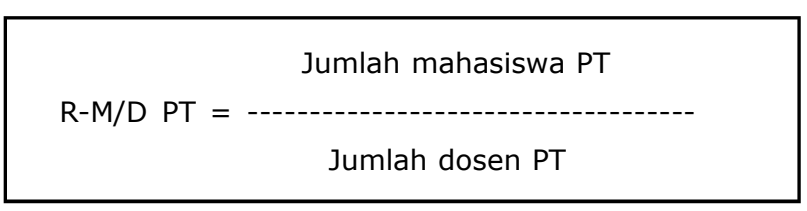

Indikator R-M/D digunakan untuk melihat seberapa banyak mahasiswa dapat dilayani oleh seorang dosen. Makin tinggi nilainya berarti dosen makin banyak melayani mahasiswa, sebaliknya makin rendah nilainya berarti makin sedikit dosen melayani mahasiswa.

Persentase MB dihitung dari jumlah mahasiswa baru PT dibagi dengan jumlah mahasiswa PT seluruhnya dan dinyatakan dalam persentase. Rumus yang digunakan adalah:

\begin{tabular}{c} 
Jumlah mahasiswa baru PT \\
J MB PT $=$ Jumlah mahasiswa PT \\
\hline
\end{tabular}

Indikator \%MB digunakan untuk melihat banyaknya mahasiswa baru yang masuk di PT. Makin tinggi nilainya berarti mahasiswa makin besar mahasiswa baru yang masuk, sebaliknya makin rendah nilainya berarti makin sedikit mahasiswa baru yang masuk.

Animo PT dihitung dari jumlah pendaftar PT dibagi dengan jumlah mahasiswa baru PT dan dinyatakan dalam persentase. Rumus yang digunakan adalah:

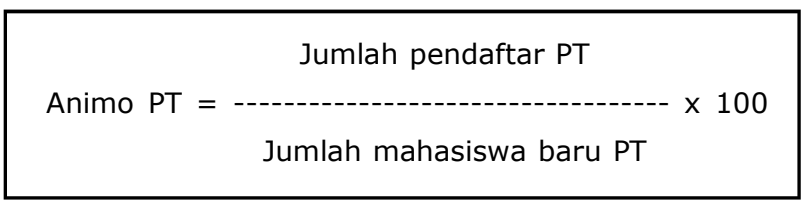

Animo PT digunakan untuk melihat besarnya lulusan SM yang masuk ke PT. Makin besar nilainya berarti makin besar animo masuk ke PT, sebaliknya makin kecil nilainya berarti makin sedikit animo masuk ke PT.

Animo PT juga terjadi pada pendidikan di Jepang, hal ini disebabkan banyaknya pendaftar dibandingkan dengan mahasiswa baru yang akan diterima. Untuk masuk PT, lulusan SMA sebagai pendaftar masuk PT diharuskan mengikuti ujian masuk universitas berskala nasional. Ujian masuk 
PT dilakukan dua tahap, yaitu 1) secara nasional disusun oleh Ministry of Education yang terdiri dari lima subjek dan 2) ujian masuk yang dilakukan di PT masing-masing. Skor kelulusan adalah akumulasi ujian masuk nasional dan ujian masuk di setiap PT. Bagi mereka yang memiliki skor tinggi dapat memilih PT pilihan pertama sedangkan yang memiliki skor lebih rendah maka dapat mengacu pada pilihan PT yang kedua. (Ramli, 2008).

Untuk menentukan bahwa pendidikan tinggi tersebut sudah merata maka digunakan lima indikator pemerataan. Oleh karena masing-masing indikator memiliki pengaruh yang berbeda maka setiap indikator diberikan bobot berbeda. APK diberi bobot paling tinggi yaitu $0,5, \%, \mathrm{R}-\mathrm{M} / \mathrm{Lbg}$ dan R-M/D diberi bobot masing-masing 0,20, dan Animo PT diberi bobot 0,1 . Nilai bobot lima indikator adalah 1. R-M/Lbg dan R-M/D dikonversi menjadi persentase dengan cara nilai R-M/Lbg dibagi dengan nilai R-M/Lbg nasional demikian juga R-M/ $D$ dibagi dengan nilai R-M/D nasional. (Pusat Statistik Pendidikan, 2008a).

Sejalan dengan program pemerataan dan perluasan akses pendidikan maka peningkatan mutu untuk semua jenjang pendidikan melalui pendidikan formal maupun nonformal juga dilaksanakan. Dianggap bermutu jika memenuhi suatu standar tertentu. Oleh karena itu, peningkatan mutu diarahkan menuju suatu standar tertentu. Peningkatan mutu dapat dilaksanakan pada masukan, keluaran, proses, guru, sarana/ prasarana dan biaya yang dikeluarkan untuk pendidikan. Peningkatan mutu diharapkan dapat memberikan dampak bagi perwujudan eksistensi manusia. Peningkatan mutu dan relevansi dapat meningkatkan taraf hidup masyarakat serta daya saing bangsa dan dapat diukur dari pencapaian kecakapan akademik dan nonakademik yang lebih tinggi sehingga lulusan dapat bertahan dalam perubahan masyarakat dalam berbagai bidang baik di tingkat provinsi, nasional maupun global. (Mahdiansyah, 2008)

Untuk mengukur tingkat mutu minimal penyelenggaraan pendidikan tinggi telah dilakukan oleh Badan Akreditasi Nasional (BAN) melalui proses akreditasi pada program studi. Oleh karena itu, BAN dihadapkan pada permasalahan banyaknya program studi yang harus diakreditas sedangkan pada saat yang sama BAN harus menjaga kredibili- tas proses dan hasil akreditasi. Untuk mengukur peningkatan mutu PT maka digunakan beberapa indikator kunci. Indikator kunci utama di tingkat nasional adalah persentase dosen layak mengajar (\%DL) (Departemen Pendidikan Nasional, 2006b). $\% \mathrm{DL}$ didefinisikan sebagai perbandingan antara jumlah dosen yang layak mengajar dikaitkan dengan ijazah yang dimiliki (Magister dan lebih tinggi) dengan jumlah dosen seluruhnya dan dinyatakan dalam persentase. Dosen layak mengajar disesuaikan dengan Undang-Undang Nomor 14, Tahun 2005 tentang Guru dan Dosen yaitu untuk semua jenjang TK sampai SMK adalah lulusan sarjana atau S1 ke atas sedangkan untuk pendidikan tinggi khusus program Diploma dan S1 adalah lulusan $\mathrm{S} 2$ atau magister sedangkan program S2 dan lebih tinggi adalah lulusan S3 atau doktor. Rumus yang digunakan adalah:

\begin{tabular}{c} 
Jumlah dosen layak mengajar PT \\
\% DL PT = Jumlah Dosen PT \\
\hline
\end{tabular}

Idealnya, \%DL adalah 100 persen, artinya semua dosen berijazah layak mengajar.

Selain indikator kunci yang digunakan di tingkat nasional maka terdapat indikator lain yang dapat digunakan untuk mengukur mutu pendidikan, yaitu 1) angka produktivitas (AProduk) dan 2) rasio dosen per lembaga (R-D/Lbg). Upaya peningkatan mutu dan relevansi pendidikan tinggi akan dilakukan pemerintah pusat, pemerintah daerah, dan perguruan tinggi (PT) secara terpadu dengan pengelolaan secara terpusat. Penilaian mutu mengacu pada Standar Nasional Pendidikan (SNP) dan pelaksanaan akreditasi dilakukan secara independen oleh Badan Akreditasi Nasional Perguruan Tinggi (BAN PT). (Mahdiansyah, 2008).

Produk dihitung dari jumlah lulusan dibagi dengan jumlah mahasiswa seluruhnya dan dinyatakan dalam persentase. Rumus yang digunakan adalah:

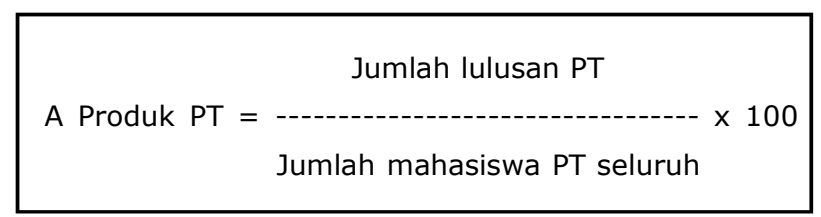

Untuk AProduk makin tinggi makin baik berarti makin banyak mahasiswa yang lulus, namun 
maksimalnya adalah 25,0\%, yaitu seperempat mahasiswa setiap tahun dapat lulus.

R-D/Lbg dihitung dari pembagian antara dosen terhadap lembaga atau rata-rata dosen di setiap lembaga PT. Rumus yang digunakan adalah:

\section{Jumlah dosen PT}

$\mathrm{R}-\mathrm{D} / \mathrm{Lbg} \mathrm{PT}=$

Jumlah lembaga PT

Untuk R-D/Lbg makin tinggi makin baik berarti makin banyak dosen yang mengajar di suatu PT. Untuk menentukan bahwa pendidikan tinggi tersebut sudah bermutu maka digunakan tiga indikator mutu, yaitu 1) \%DL, 2) Aproduk, dan 3) R-D/Lg. Selain itu, oleh karena masing-masing indikator memiliki pengaruh yang berbeda maka setiap indikator diberikan bobot berbeda. \%DL diberi bobot paling tinggi yaitu $0,5, \%$, AProduk diberi bobot 0,30, dan R-D/Lbg diberi bobot 0,2 R-D/Lbg dikonversi menjadi persentase dengan cara nilai R-D/Lbg dibagi dengan R-D/Lbg nasional. Nilai bobot tiga indikator adalah 1. (Pusat Statistik Pendidikan, 2008a).

\section{Kinerja Pendidikan Tinggi}

Kinerja pendidikan dinyatakan dalam tiga pilar kebijakan program pembangunan pendidikan. Namun, untuk kinerja pendidikan tinggi dinilai dari rata-rata dua pilar kebijakan program pembangunan pendidikan tinggi. Rata-rata tersebut dihitung dari semua nilai "Jumlah" angka semua indikator setelah diberi bobot. (Ida Kintamani, 2009a). Pemilihan kedua kelompok indikator dengan ke-7 jenis indikator, yaitu 1) APK, 2) R-M/ Lbg, 3) R-M/D, 4) \% Animo, 5) \% DL, 6) Aproduk, dan 7) R-D/Lbg dianggap yang paling tepat mengukur kinerja pendidikan tinggi. (Pusat Statistik Pendidikan, 2008a). Dengan demikian, dapat disimpulkan bahwa kinerja pendidikan adalah jumlah nilai pemerataan pendidikan tinggi dan mutu pendidikan tinggi dibagi dua atau ratarata dari kedua nilai tersebut. Bila nilai pemerataan pendidikan adalah 85 dan nilai mutu pendidikan adalah 60 dijumlahkan dan dibagi dengan angka dua maka keberhasilan pendidikan adalah 72,5 atau pendidikan telah tercapai $72,5 \%$ dan sisanya $27,5 \%$ belum berhasil.

Agar dapat diukur kinerjanya maka hasil indikator pemerataan ditambah dengan hasil indikator mutu hasilnya adalah kinerja pendidikan tinggi. Rumus yang digunakan adalah:

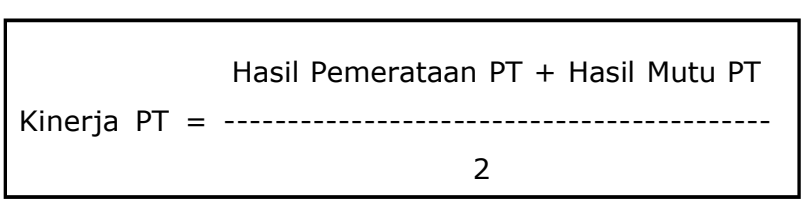

Kinerja pendidikan tinggi nasional dapat digunakan sebagai standar nasional pencapaian sedangkan standar idealnya adalah 100\%. Tabel 1 merupakan perhitungan kinerja nasional yang hasilnya dibandingkan dengan standar ideal. (Pusat Statistik Pendidikan, 2008a).

Tabel 1. Perhitungan Kinerja PT Nasional

Tahun 2008/2009

\begin{tabular}{|l|l|l|r|r|r|r|r|}
\hline No. & Pilar Kebijakan & Indikator & Nasional & Konversi & Bobot & SN & SI \\
\hline \multirow{4}{*}{1.} & \multirow{2}{*}{ Pemerataan } & APK & 12,9 & & 0.5 & 6.20 & \\
\cline { 3 - 8 } & & R-M/Lbg & 1342.43 & 100 & 0.2 & 20.00 & \\
\cline { 3 - 8 } & & R-M/D & 14.19 & 100 & 0.2 & 20.00 & \\
\cline { 3 - 8 } & & \%Animo & 216.13 & & 0.1 & 21.61 & \\
\cline { 3 - 8 } & & Jumlah & & & & 67.81 & 100.00 \\
\hline \multirow{3}{*}{2.} & Mutu & \%DL & 44.56 & & 0.5 & 22.28 & \\
\cline { 3 - 8 } & & Aproduk & 7.94 & & 0.2 & 1.59 & \\
\cline { 3 - 8 } & & R-D/Lbg & 94.63 & 100 & 0.2 & 20.00 & \\
\cline { 3 - 8 } & & & & & & 43.87 & 100.00 \\
\hline 3. & Kumlah & & & & 55.84 & 100.00 \\
\hline
\end{tabular}

Catatan: SN adalah standar nasional dan SI adalah standar ideal 


\section{Hasil dan Pembahasan}

Untuk melaksanakan analisis profil pendidikan PT maka digunakan indikator kinerja program pembangunan pendidikan tinggi di Provinsi Bali. Untuk itu, akan dijelaskan tentang empat hal yang menjadi tujuan, yaitu: 1) keadaan nonpendidikan; 2) keadaan pendidikan tinggi; 3) hasil indikator pendidikan tinggi; dan 4) kinerja pendidikan tinggi dalam rangka memberikan bahan untuk perumusan kebijakan dan perencanaan pendidikan tinggi di Provinsi Bali.

\section{Keadaan Nonpendidikan}

Dalam rangka analisis profil pendidikan tinggi di Provinsi Bali maka perlu dipahami terlebih dahulu daerahnya dengan menjelaskan tentang keadaan nonpendidikan yang ada di Provinsi Bali. Provinsi Bali terletak pada pada $8^{\circ} 3^{\prime} 40^{\prime \prime}$ - 8 $8^{\circ} 50^{\prime} 48^{\prime \prime}$ Lintang Selatan dan $114^{\circ} 25^{\prime} 53^{\prime \prime}$ - $115^{\circ} 42^{\prime} 40^{\prime \prime}$ Bujur Timur. Relief dan topografi Provinsi Bali di tengah-tengah terbentang pegunungan yang memanjang dari barat ke timur. Provinsi Bali terletak di antara pulau Jawa dan pulau Lombok. Pada bagian utara dibatasi dengan Laut Bali, bagian timur dibatasi dengan Selat Lombok, bagian selatan dengan Samudera Indonesia, dan bagian barat dengan Selat Bali.

Provinsi Bali terbagi menjadi 8 kabupaten dan satu kota, yaitu Kabupaten Jembrana, Kabupaten Tabanan, Kabupaten Badung, Kabupaten Gianyar, Kabupaten Karangasem, Kabupaten Klungkung, Kabupaten Bangli, Kabupaten Buleleng, dan Kota
Denpasar. Kota Denpasar juga merupakan ibukota Provinsi Bali. Selain pulau Bali, provinsi Bali juga memiliki pulau-pulau kecil seperti pulau Nusa Penida, Nusa Lembongan, dan Nusa Ceningan yang termasuk wilayah kabupaten Klungkung, pulau Serangan termasuk wilayah Kota Denpasar, dan pulau Menjangan termasuk kabupaten Buleleng.

Luas provinsi Bali secara keseluruhan sebesar $5.634,40$ ha dan panjang pantai mencapai 529 $\mathrm{km}$. Provinsi Bali merupakan daerah pegunungan dan perbukitan yang meliputi sebagian besar wilayah. Relief Pulau Bali merupakan rantai pegunungan yang memanjang dari barat ke timur. Di antara pegunungan itu, terdapat gunung berapi yang masih aktif, yaitu Gunung Agung (3.142 m) dan Gunung Batur $(1.717 \mathrm{~m})$. Beberapa gunung yang tidak aktif lainnya mencapai ketinggian antara $1.000-2.000 \mathrm{~m}$.

Rantai pegunungan yang membentang di bagian tengah Pulau Bali menyebabkan wilayah ini secara geografis terbagi menjadi dua bagian, yaitu Bali Utara dengan dataran rendah yang sempit dari kaki perbukitan dan pegunungan dan Bali selatan dengan dataran rendah yang luas dan landai. Ditinjau dari kemiringan lerengnya, Pulau Bali sebagian besar terdiri atas lahan dengan kemiringan antara 0-2\% sampai $15-40 \%$. Selebihnya adalah lahan dengan kemiringan di atas 40\%. (www.baliprov.go.id).

Berdasarkan Tabel 2 dapat diketahui penduduk usia masuk sekolah dan usia sekolah

Peta Provinsi Bali

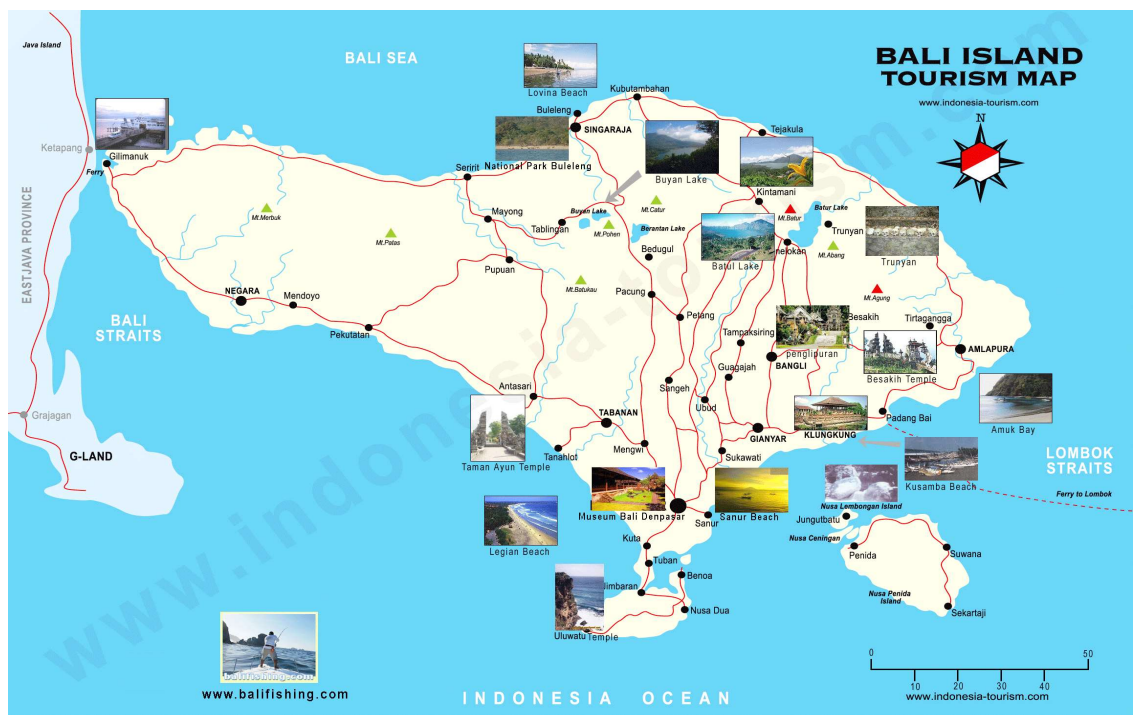


Tabel 2. Data Nonpendidikan (Penduduk Usia Masuk dan Usia Sekolah), Provinsi Bali Tahun 2008

\begin{tabular}{|c|c|c|c|c|c|}
\hline \multirow[t]{2}{*}{ No. } & \multirow{2}{*}{$\begin{array}{l}\text { Jenjang } \\
\text { Pendidikan }\end{array}$} & \multicolumn{4}{|c|}{ Penduduk } \\
\hline & & $\begin{array}{l}\text { Usia } \\
\text { Masuk }\end{array}$ & Jumlah & $\begin{array}{l}\text { Usia } \\
\text { Sekolah }\end{array}$ & Jumlah \\
\hline 1. & TK & 4-5 tahun & 103.000 & 4-6 tahun & 157.485 \\
\hline 2. & SD/MI & 6-7 tahun & 111.000 & $7-12$ tahun & 342.290 \\
\hline 3. & SMP/MTs & & & 13-15 tahun & 172.102 \\
\hline 4. & SM/MA & & & 16-18 tahun & 153,536 \\
\hline 5. & PT & & & 19-24 tahun & 333.300 \\
\hline
\end{tabular}

pada setiap jenjang pendidikan. Untuk TK, usia masuk TK adalah 4-5 tahun sebesar 103.000 sedangkan kelompok usia TK adalah 4-6 tahun sebesar 157.485. Untuk SD, usia masuk SD adalah 6-7 tahun sebesar 115.500 sedangkan kelompok usia SD adalah 7-12 tahun sebesar 342.290. Selanjutnya, kelompok usia SMP adalah 13-15 tahun sebesar 172.102, kelompok usia SM adalah 16-18 tahun sebesar 153.536 dan kelompok usia PT adalah 19-24 tahun sebesar 333.300 .

\section{Keadaan Pendidikan Tinggi}

Bahasan tentang keadaan pendidikan tinggi dilihat dari data pendidikan tinggi pada tahun akademik 2008/2009. Berdasarkan Tabel 3, Provinsi Bali memiliki lima jenis lembaga, yaitu: 1) universitas, 2) institut, 3) ST, 4) akademi, dan 5) politeknik. Bila dilihat dari status lembaganya maka terdapat lembaga Negeri maupun Swasta. Untuk status Negeri terdapat 2 universitas (Universitas Udayana dan Universitas Pendidikan Ganesha), 1 institut (Institut Seni Indonesia

Tabel 3. Gambaran Umum Pendidikan Tinggi, Provinsi Bali Tahun 2008/2009

\begin{tabular}{|c|c|c|c|c|c|c|c|c|c|c|c|c|}
\hline No. & Variabel & $\begin{array}{l}\text { Univer- } \\
\text { sitas }\end{array}$ & $\%$ & $\begin{array}{r}\text { Insti- } \\
\text { tut }\end{array}$ & $\%$ & ST & $\%$ & $\begin{array}{l}\text { Aka- } \\
\text { demi }\end{array}$ & $\%$ & $\begin{array}{l}\text { Poli- } \\
\text { teknik }\end{array}$ & $\%$ & Jumlah \\
\hline \multirow[t]{3}{*}{1.} & Lembaga & 11 & 30.56 & 3 & 8.33 & 15 & 41.67 & 4 & 11.11 & 3 & 8.33 & 36 \\
\hline & a. Negeri & 2 & 50.00 & 1 & 25.00 & 0 & 0.00 & 0 & 0.00 & 1 & 25.00 & 4 \\
\hline & b. Swasta & 9 & 28.13 & 2 & 6.25 & 15 & 46.88 & 4 & 12.50 & 2 & 6.25 & 32 \\
\hline \multirow[t]{3}{*}{2.} & Pendaftar & 10,433 & 57.09 & 4,314 & 23.60 & 2,537 & 13.88 & 149 & 0.82 & 843 & 4.61 & 18,276 \\
\hline & a. Negeri & 5,699 & 54.57 & 3,946 & 37.78 & 0 & 0.00 & 0 & 0.00 & 799 & 7.65 & 10.444 \\
\hline & b. Swasta & 4,734 & 60.44 & 368 & 4.70 & 2,537 & 32.39 & 149 & 1.90 & 44 & 0.56 & 7,832 \\
\hline \multirow[t]{3}{*}{3.} & Mahasiswa Baru & 7,316 & 58.15 & 2,134 & 16.96 & 2,294 & 18.23 & 271 & 2.15 & 566 & 4.50 & 12,581 \\
\hline & a. Negeri & 3,115 & 57.44 & 1,781 & 32.84 & 0 & 0.00 & 0 & 0.00 & 527 & 9.72 & 5,423 \\
\hline & b. Swasta & 4,201 & 58.69 & 353 & 4.93 & 2,294 & 32.05 & 271 & 3.79 & 39 & 0.54 & 7.158 \\
\hline \multirow[t]{3}{*}{4.} & Mahasiswa & 26,515 & 70.88 & 1,925 & 5.15 & 7,042 & 18.83 & 643 & 1.72 & 1,282 & 3.43 & 37,407 \\
\hline & a. Negeri & 11,666 & 86.04 & 704 & 5.19 & 0 & 0.00 & 0 & 0.00 & 1,189 & 8.77 & 13.559 \\
\hline & b. Swasta & 14,849 & 62.27 & 1,221 & 5.12 & 7,042 & 29.53 & 643 & 270 & 93 & 0.39 & 23.848 \\
\hline \multirow[t]{3}{*}{5.} & Lulusan & 1,844 & 69.98 & 377 & 14.31 & 337 & 12.79 & 33 & 1.25 & 44 & 1.67 & 2,635 \\
\hline & a. Negeri & 898 & 70.99 & 326 & 25.77 & 0 & 0.00 & 0 & 0.00 & 41 & 3.24 & 1,265 \\
\hline & b. Swasta & 946 & 69.05 & 51 & 3.72 & 337 & 24.60 & 33 & 2.41 & 3 & 0.22 & 1,370 \\
\hline \multirow[t]{3}{*}{6.} & Dosen & 1,590 & 56.48 & 624 & 22.17 & 215 & 7.64 & 88 & 3.13 & 298 & 10.59 & 2,815 \\
\hline & a. Negeri & 1,462 & 63.24 & 584 & 25.26 & 0 & 0.00 & 0 & 0.00 & 266 & 11.51 & 2,312 \\
\hline & b. Swasta & 128 & 25.45 & 40 & 7.95 & 215 & 4274 & 88 & 17.50 & 32 & 6.36 & 503 \\
\hline
\end{tabular}

Sumber: Kuesioner Pendidikan Tinggi Prov. Bali, 2008 
Denpasar), dan 1 politeknik (Politeknik Negeri Bali) sedangkan untuk status Swasta terdapat 9 universitas, 2 institut, 15 ST, 4 Akademi, dan 2 politeknik sehingga jumlahnya 32 lembaga. Dengan demikian, jumlah lembaga PT seluruhnya adalah 36 PT dengan rincian 11 Universitas, 3 institut, $15 \mathrm{ST}, 4$ akademi, dan 3 politeknik.

Jumlah pendaftar PT di Bali pada tahun 2008/ 2009 sebesar 18.276 orang dan terdiri dari pendaftar PT Negeri sebesar 10.444 orang lebih banyak daripada PT Swasta sebesar 7.832 orang. Berdasarkan jenis lembaga maka pendaftar pada Universitas terbesar sebanyak 10.433 orang (57,09\%) dan terkecil pada Akademi sebanyak 149 orang $(0,82 \%)$. Pendaftar menurut status lembaga yaitu PT Negeri dan PT Swasta terbesar juga pada Universitas masing-masing sebanyak 5.699 orang $(54,57 \%)$ dan 4.734 orang $(60,44 \%)$ dan terkecil pada Akademi sebesar 149 orang $(1,90 \%)$. Bila dikaitkan dengan mahasiswa baru PT maka dari 18.276 orang pendaftar PT hanya 12.581 orang yang menjadi mahasiswa baru PT. Bila dilihat menurut jenis lembaga mahasiswa baru universitas yang terbesar sebanyak 7.316 orang $(58,15 \%)$ dan terkecil pada Akademi sebesar 271 orang $(2,15 \%)$. Bila dilihat menurut status lembaga maka mahasiswa baru PT Negeri dan Swasta pada universitas yang terbesar masingmasing sebanyak 3.115 orang $(57,44 \%)$ dan 4.201 orang $(58,69 \%)$. Sebaliknya, yang terkecil untuk PT Negeri dan PT Swasta adalah Politeknik masing-masing sebesar 527 orang $(9,72 \%)$ dan 39 orang $(0,54 \%)$.

Jumlah mahasiswa PT di Bali pada tahun 2008/2009 adalah sebanyak 37.407 orang berada di PT Negeri sebanyak 13.559 orang dan di PT Swasta sebanyak 23.848 orang. Jumlah mahasiswa terbesar di universitas sebanyak 26.515 orang $(70,88 \%)$ dan terkecil di Akademi sebanyak 643 orang $(1,72 \%)$. Baik PT Negeri maupun Swasta mahasiswa terbesar pada universitas dengan rincian PT Negeri sebesar 11.666 orang $(86,04 \%)$ dan PT Swasta sebesar 14.849 orang $(62,27 \%)$. Sebaliknya, yang terkecil untuk PT Negeri dan PT Swasta adalah Politeknik masing-masing sebesar 1.189 orang $(8,77 \%)$ dan 93 orang $(0,39 \%)$.

Jumlah lulusan PT di Bali pada tahun 2008/ 2009 adalah sebanyak 2.635 orang dengan lulusan dari PT Negeri sebanyak 1.265 orang dan dari PT Swasta sebanyak 1.370 orang. Bila dilihat per jenis lembaga maka lulusan PT terbanyak juga pada universitas sebesar 1.844 orang $(69,98 \%)$ dan terkecil pada Akademi sebesar 33 orang $(1,25 \%)$. Lulusan PT universitas yang terbesar sebanyak 1.844 orang $(69,98 \%)$ dengan rincian Negeri sebesar 898 orang $(70,99 \%)$ dan Swasta sebesar 946 orang $(69,05 \%)$. Sebaliknya, yang terkecil untuk PT Negeri dan PT Swasta adalah Politeknik masing-masing sebesar 41 orang $(3,24 \%)$ dan 3 orang $(0,22 \%)$.

Jumlah dosen PT di Bali pada tahun 2008/2009 adalah sebanyak 2.615 orang dengan dosen dari PT Negeri sebanyak 2.312 orang dan dari PT Swasta sebanyak 503 orang. Bila dilihat per jenis lembaga maka dosen terbanyak juga pada universitas sebesar 1.590 orang $(56,48 \%)$ dan terkecil pada Akademi sebesar 88 orang (3,13\%). Dosen PT Negeri terbesar pada universitas sebesar 1.462 orang $(63,24 \%)$ dan Swasta sebesar $128(25,45 \%)$. Sebaliknya, yang terkecil

Tabel 4. Indikator Pemerataan Pendidikan, Provinsi Bali Tahun 2008/2009

\begin{tabular}{|c|c|c|}
\hline No. & Indikator & Nilai \\
\hline \multirow[t]{5}{*}{1.} & APK (\%) & 11.22 \\
\hline & a. Laki2 & 11.74 \\
\hline & b. Perempuan & 10.67 \\
\hline & Dispatitas Gender & 1.06 \\
\hline & Indeks Paritas Gender & $\overline{0.91}$ \\
\hline \multirow[t]{3}{*}{2.} & $\%$ Mahasiswa & \\
\hline & a. Laki2 & 54.09 \\
\hline & b. Perempuan & 45.91 \\
\hline \multirow[t]{3}{*}{3.} & Rasio Mahasiswa per Lembaga & 1,039 \\
\hline & a. Negeri & 3,390 \\
\hline & b. Swasta & 745 \\
\hline \multirow[t]{3}{*}{4.} & Rasio Mahasiswa per Dosen & 13 \\
\hline & a. Negeri & 6 \\
\hline & b. Swasta & 47 \\
\hline \multirow[t]{3}{*}{5.} & $\begin{array}{l}\text { \% Mahasiswa Baru thd maha- } \\
\text { siswa }\end{array}$ & 33.31 \\
\hline & a. Negeri & 40.00 \\
\hline & b. Swasta & 29.50 \\
\hline \multirow[t]{7}{*}{6.} & $\%$ Animo ke PT & 147.67 \\
\hline & a. SO & 285.69 \\
\hline & b. S1 & 130.18 \\
\hline & c. S2 & 238.10 \\
\hline & d. S3 & 183.33 \\
\hline & e. Negeri & 192.59 \\
\hline & b. Swasta & 113.05 \\
\hline
\end{tabular}


Tabel 5. Indikator Pemerataan menurut Jenis Lembaga PT, Provinsi Bali Tahun 2008/2009

\begin{tabular}{|l|l|r|r|r|r|r|r|}
\hline No. & Indikator & $\begin{array}{r}\text { Univer- } \\
\text { sitas }\end{array}$ & Institut & ST & $\begin{array}{r}\text { Aka- } \\
\text { demi }\end{array}$ & $\begin{array}{r}\text { Poli- } \\
\text { teknik }\end{array}$ & Rata2 \\
\hline \multirow{2}{*}{1.} & Rasio Mahasiswa Lembaga & 2,410 & 642 & 469 & 161 & 427 & 1,039 \\
\cline { 2 - 7 } & a. Negeri & 5,833 & 704 & 0 & 0 & 1,189 & 3,390 \\
\cline { 2 - 8 } & b. Swasta & 1,650 & 611 & 469 & 161 & 47 & 745 \\
\hline \multirow{2}{*}{2.} & Rasio Mahasiswa Dosen & 17 & 3 & 33 & 7 & 4 & 13 \\
\cline { 2 - 8 } & a. Negeri & 8 & 1 & 0 & 0 & 4 & 6 \\
\cline { 2 - 8 } & b. Swasta & 116 & 31 & 33 & 7 & 3 & 47 \\
\hline \multirow{3}{*}{3.} & $\%$ Mhs Baru thd Mhasiswa & 27.59 & 110.86 & 32.58 & 23.17 & 44.15 & 33.31 \\
\cline { 2 - 8 } & a. Negeri & 26.70 & 252.98 & 0.00 & 0.00 & 44.32 & 40.00 \\
\cline { 2 - 8 } & b. Swasta & 28.29 & 28.91 & 32.58 & 23.17 & 41.94 & 29.50 \\
\hline \multirow{3}{*}{4.} & $\%$ Animo ke PT & 141.61 & 202.16 & 110.59 & 181.88 & 148.94 & 147.67 \\
\cline { 2 - 8 } & a. Negeri & 182.95 & 221.56 & 0.00 & 0.00 & 151.61 & 192.59 \\
\cline { 2 - 8 } & b. Swasta & 112.69 & 104.25 & 110.59 & 181.88 & 112.82 & 113.05 \\
\hline
\end{tabular}

untuk PT Negeri dan PT Swasta adalah Politeknik masing-masing sebesar 266 orang $(11,51 \%)$ dan 32 orang $(6,36 \%)$.

\section{Hasil Indikator Pendidikan Tinggi}

Kajian indikator pendidikan tinggi hanya difokuskan pada dua pilar kebijakan, yaitu 1) pemerataan dan perluasan akses pendidikan dan 2) peningkatan mutu, relevansi, dan daya saing pendidikan. Untuk menerapkan dua pilar kebijakan tersebut maka indikator pendidikan yang digunakan dibagi menjadi dua jenis, yaitu 1 ) indikator pemerataan dan 2) indikator mutu.

Berdasarkan Tabel 4, APK PT di Provinsi Bali adalah sebesar $11,22 \%$. Bila dibandingkan antara jenis kelamin maka APK PT laki-laki sebesar $11,74 \%$ lebih besar jika dibandingkan dengan APK PT perempuan sebesar $10,67 \%$. Dengan demikian, terdapat perbedaan gender sebesar $1,06 \%$ sehingga terjadi ketidakseimbangan gender dengan indeks paritas gender sebesar 0,91 . Data ini menunjukkan bahwa partisipasi mahasiswa menurut gender belum seimbang. Antara laki-laki dan perempuan nilainya tidak sama dengan 1 dan laki-laki lebih baik partisipasinya daripada perempuan. Persentase mahasiswa lakilaki $(54,09 \%)$ ternyata juga lebih besar jika dibandingkan dengan perempuan (45,91\%).

Berdasarkan Tabel 4 dan 5 dapat diketahui kepadatan mahasiswa sebesar 1.039 orang sedangkan kepadatan di PT Negeri sebesar 3.390 orang dan PT Swasta sebesar 745 orang. Hal ini berarti kepadatan mahasiswa PT swasta hanya 22,0\% dari PT Negeri. Bila dibandingkan untuk jenis PT maka Universitas adalah yang terpadat (2.410 orang) dan terjarang adalah Akademi (161 orang). Kepadatan universitas yang dirinci menjadi Negeri dan Swasta maka di PT Negeri adalah sebesar 5.833 orang $(72,7 \%)$ sedangkan di PT Swasta sebesar 1.650 orang $(27,3 \%)$ atau PT Swasta hanya $28,3 \%$ dari PT Negeri. ST hanya di PT Swasta cukup besar dengan rata-rata sebesar 469.

Tabel 4 dan 5 menunjukkan efektivitas belajar mengajar di PT Bali. R-M/D sebesar 13, berarti seorang dosen melayani 13 mahasiswa. Menurut status lembaga ternyata dosen PT Negeri melayani 6 mahasiswa sedangkan dosen PT Swasta melayani 47 mahasiswa. Hal ini berarti dosen di PT Swasta melayani mahasiswa 7 kali lebih banyak daripada PT Negeri. Pada universitas Negeri seorang dosen melayani 8 mahasiswa sedangkan universitas Swasta melayani 116 mahasiswa. Untuk Politeknik baik Negeri maupun Swasta bebannya agak sama, yaitu satu dosen untuk 4 dan 3 mahasiswa. R-M/D terbesar terdapat pada ST Swasta, yaitu satu dosen menangani 33 mahasiswa. Rasio terkecil ada di Politeknik, satu dosen menangani 3 mahasiswa.

Pada kenyataannya, persentase mahasiswa baru terhadap mahasiswa di PT Bali sebesar $33,63 \%$ dengan rincian PT Negeri sebesar $40,00 \%$ dan Swasta sebesar 29,50\%. Hal ini berarti mahasiswa baru di PT Negeri lebih banyak 
Tabel 6. Indikator Mutu Pendidikan Tinggi, Provinsi Bali Tahun 2008/2009

\begin{tabular}{|l|l|r|r|r|r|r|}
\hline No. & Indikator & Laki2 & $\begin{array}{r}\text { Perem- } \\
\text { puan }\end{array}$ & Rata2 & PG & IPG \\
\hline \multirow{3}{*}{1.} & Kekayaan Mengajar Dosen & 52.80 & 47.47 & 50.55 & 5.32 & 0.90 \\
\cline { 2 - 7 } & a. Negeri & 57.65 & 52.48 & 55.49 & 5.17 & 0.91 \\
\cline { 2 - 7 } & b. Swasta & 29.54 & 25.68 & 27.83 & 3.86 & 0.87 \\
\hline \multirow{3}{*}{2.} & Angka Produktivitas & 7.067 & 7.03 & 7.04 & 0.03 & 1.00 \\
\cline { 2 - 7 } & a. SO & 8.50 & 8.57 & 8.54 & -0.06 & 1.01 \\
\cline { 2 - 7 } & b. S1 & 6.78 & 6.68 & 6.74 & 0.11 & 0.98 \\
\cline { 2 - 7 } & c. S2 & 9.30 & 9.35 & 9.32 & -0.05 & 1.01 \\
\cline { 2 - 7 } & d. S3 & 9.09 & 8.33 & 8.82 & 0.76 & 0.92 \\
\cline { 2 - 7 } & e. Negeri & 9.33 & 9.33 & 9.33 & 0.00 & 1.00 \\
\cline { 2 - 7 } & f. Swasta & 5.84 & 5.62 & 5.74 & 0.22 & 0.96 \\
\hline
\end{tabular}

daripada PT Swasta. Bila dirinci menurut jenis lembaga maka persentase mahasiswa baru pada universitas adalah sebesar 27,59\% dan PT Negeri sebesar 26,70\% lebih kecil daripada PT Swasta sebesar 28,29\%. Persentase mahasiswa baru terbesar pada Politeknik sebesar $44,15 \%$ dengan rincian PT Negeri sebesar 44,32\% dan PT Swasta sebesar 41,94\%. (Tabel 4 dan 5).

Animo ke PT ternyata sangat tinggi dan melebihi $100 \%$. Hal ini diakibatkan lulusan SM boleh mendaftar di beberapa jenis lembaga PT. (Ramli, 2008). Animo ke PT di Bali sebesar $145,67 \%$ yang merupakan rata-rata untuk jenjang pendidikan S0, S1, S2, dan S3. Animo ke jenjang S0 yang tertinggi, yaitu $285,69 \%$ sedangkan yang terrendah adalah animo ke jenjang S1 sebesar 130,18\%. Bila dibandingkan antara PT Negeri dan PT Swasta maka animo ke PT Negeri sangat besar, yaitu 192,59\% sedangkan ke PT Swasta hanya 113,05\%. Dilihat menurut jenis lembaga maka animo ke Institut menunjuk- kan angka terbesar $(202,16 \%)$ dan terkecil pada ST $(110,59 \%)$. Animo ke universitas pada PT Negeri sebesar 192,59\% lebih tinggi dibandingkan dengan ke PT Swasta sebesar 113,05\%.

Tabel 6 memperlihatkan bahwa persentase dosen PT layak mengajar di Bali pada tahun 2008/ 2009 adalah sebesar 50,55\% terdiri dari laki-laki sebesar $52,80 \%$ dan perempuan sebesar $47,47 \%$. Dengan demikian, terjadi perbedaan gender sebesar 5,32\% dengan indeks paritas gender sebesar 0,90 atau masih belum seimbang karena disebut seimbang jika nilainya 1. (Pusat Statistik Pendidikan, 2008b). Bila dibandingkan antara PT Negeri dan PT Swasta maka persentase dosen layak mengajar di PT Negeri sebesar 55,49\% dan di PT Swasta sebesar 27,83\%. Bila dibandingkan antara jenis kelamin maka persentase dosen layak mengajar PT Negeri laki-laki sebesar 57,65\% dan perempuan sebesar $52,48 \%$. Dengan demikian, terjadi perbedaan gender sebesar $5,17 \%$ dengan indeks paritas gender sebesar

Tabel 7. Indikator Mutu menurut Jenis Lembaga PT, Provinsi Bali Tahun 2008/2009

\begin{tabular}{|ll|r|r|r|r|r|r|}
\hline No. Indikator & $\begin{array}{r}\text { Univer- } \\
\text { sitas }\end{array}$ & Institut & ST & $\begin{array}{r}\text { Aka- } \\
\text { demi }\end{array}$ & $\begin{array}{r}\text { Poli- } \\
\text { teknik }\end{array}$ & Rata2 \\
\hline \multirow{2}{*}{1.} & 6.95 & 19.58 & 4.79 & 5.13 & 3.43 & 7.04 \\
\cline { 2 - 8 } & Angka Produktivitas & 7.70 & 46.31 & 0.00 & 0.00 & 3.45 & 9.33 \\
\hline & a. Negeri & 6.37 & 4.18 & 4.79 & 5.13 & 3.23 & 5.74 \\
\hline 2. & Rasio Dosen per Lembaga & 145 & 208 & 14 & 22 & 99 & 78 \\
\cline { 2 - 8 } & a. Negeri & 731 & 584 & 0 & 0 & 266 & 578 \\
\cline { 2 - 7 } & 14 & 20 & 14 & 22 & 16 & 16 \\
\hline
\end{tabular}


0,91 , berarti belum seimbang. Hal yang sama untuk PT Swasta persentase dosen layak mengajar PT Swasta laki-laki sebesar $29,54 \%$ dan perempuan sebesar 25,68\%. Dengan demikian, terjadi perbedaan gender sebesar 3,86\% dengan indeks paritas gender sebesar 0,87 , berarti masih jauh dari seimbang. Rendahnya \%DL PT menjadi penyebab rendahnya mutu pendidikan tinggi, akibat belum adanya sistem dosen pada jenjang PT. Maksud sistem dosen adalah pemberdayaan dosen pada saat ini belum bermutu baik dilihat dari segi kesejahteraan, terutama gaji dan pendidikan/pelatihan dalam jabatan. (Tampubolon, 2009).

Angka produktivitas PT di Bali pada tahun 2008/2009 diketahui sangat kecil, yaitu 7,04\%. Bila dibandingkan antara laki-laki dan perempuan maka angka produktivitas laki-laki $(7,06 \%)$ lebih besar daripada perempuan (7,03\%). Hal ini menyebabkan adanya perbedaan gender sebesar $0,03 \%$ dengan indeks paritas gender 1,00 yang telah menunjukkan seimbang. Angka produktivitas antara S0, S1, S2, dan S3 cukup bervariasi. Namun, angka produktivitas yang terendah pada S1 sebesar $6,74 \%$ dengan perbedaan gender sebesar $0,76 \%$ dan indeks paritas gender sebesar 0,92 , yang berarti belum seimbang. Tabel 7 memperlihatkan angka produktivitas yang tertinggi adalah institut sebesar $19,58 \%$ dan terkecil pada politeknik sebesar 3,43\%. Angka produktivitas pada universitas adalah sebesar $6,95 \%$ dan PT Negeri lebih besar $(7,70 \%)$ jika dibandingkan dengan PT Swasta $(6,37 \%)$.
Tabel 7 menunjukkan bahwa rasio dosen per lembaga PT di Bali adalah sebesar 78 dengan rincian PT Negeri sebesar 578 (sangat besar) jika dibandingkan dengan PT Swasta sebesar 16. Bila dilihat per jenis lembaga maka universitas yang tertinggi sebesar 145 dan terkecil pada ST sebesar 14. Bila dilihat menurut jenis dan status lembaga maka maka universitas Negeri yang terbesar sebesar 731 jika dibandingkan dengan universitas Swasta sebesar 14. Hal yang sama untuk institut Negeri sebesar 584 dengan institut Swasta sebesar 20 dan politeknik Negeri sebesar 266 dengan politeknik swasta sebesar 16 .

\section{Kinerja Pendidikan Tinggi}

Jenis indikator pendidikan pemerataan dan mutu tersebut digunakan untuk menilai keberhasilan program pembangunan pendidikan tinggi. Indikator pemerataan digunakan untuk menilai pemerataan pendidikan yang dapat dicapai, sedangkan indikator mutu digunakan untuk menilai mutu pendidikan yang dapat dicapai. Gabungan dari kedua indikator tersebut digunakan untuk menilai kinerja program pembangunan pendidikan tinggi.

Indikator pemerataan yang diambil untuk menghitung pemerataan sebanyak empat jenis, yaitu APK, R-M/Lbg, R-M/D dan Animo sedangkan indikator mutu sebanyak tiga jenis, yaitu \%DL, Aproduk, dan R-D/Lbg. Oleh karena indikator pemerataan dan mutu dalam bentuk persentase dan rasio maka indikator dalam bentuk rasio dikonversi dalam bentuk persentase. Terdapat tiga

Tabel 8. Kinerja Pendidikan Tinggi (menggunakan konversi dan bobot), Provinsi Bali Tahun 2007/2008

\begin{tabular}{|l|l|l|r|r|r|r|r|r|}
\hline No. & Pilar Kebijakan & Indikator & Nilai & $\begin{array}{r}\text { Kon- } \\
\text { versi }\end{array}$ & Bobot & Nilai & SI & SN \\
\hline \multirow{3}{*}{1.} & \multirow{2}{*}{ Pemerataan } & APK & 11.22 & & 0.5 & 5.61 & & \\
\cline { 3 - 9 } & & R-M/Lbg & 1039.08 & 77.40 & 0.2 & 15.48 & & \\
\cline { 3 - 9 } & & R-M/D & 13.29 & 93.67 & 0.2 & 18.73 & & \\
\cline { 3 - 9 } & Jumlah & & & & 54.59 & 54.59 & 80.51 \\
\hline \multirow{2}{*}{2.} & \multirow{2}{*}{ Mutu } & \% DL & 50.55 & & 0.5 & 25.28 & & \\
\cline { 3 - 9 } & Aproduk & 7.04 & & 0.3 & 2.11 & & \\
\cline { 3 - 9 } & R-D/Lbg & 78.19 & 82.64 & 0.2 & 16.53 & & \\
\hline & Jumlah & & & & 43.92 & 43.92 & 100.11 \\
\hline 3. & Kinerja & & & & & 49.25 & 49.25 & 88.21 \\
\hline
\end{tabular}


indikator yang harus mengalami konversi, yaitu R-M/Lbg, R-M/D, dan R-D/Lbg. Dalam menentukan konversi maka digunakan nilai nasional. Artinya, nilai yang kurang dari nasional menghasilkan nilai konversi kurang dari $100 \%$, sebaliknya yang lebih dari nilai nasional konversinya menjadi $=100 \%$.

Nilai pendidikan merata adalah penjumlahan dari empat jenis indikator pemerataan setelah dikonversi dan diberikan bobot. Nilai pendidikan bermutu adalah penjumlahan dari tiga indikator mutu setelah diberikan bobot. Nilai kinerja pendidikan adalah penjumlahan nilai pendidikan merata dan pendidikan bermutu kemudian dibagi 2. Nilai maksimal untuk masing-masing indikator dan kinerja program pembangunan pendidikan adalah 100.

Tabel 8 menunjukkan kinerja pendidikan tinggi yang dihitung dari nilai pendidikan merata dan pendidikan bermutu. Nilai pemerataan berdasarkan 4 jenis indikator sebesar 54,59 sedangkan nilai mutu berdasarkan 3 jenis indikator sebesar 43,92 sehingga kinerja menjadi 49,25 . Dengan menggunakan standar ideal sebesar $100 \%$ maka kinerja yang diperoleh sebesar $49,25 \%$ sedangkan dengan menggunakan standar nasional sebesar 55,84 maka kinerja PT di provinsi Bali sebesar $88,21 \%$. Dengan demikian, masih ada $11,79 \%$ yang harus dituntaskan jika menggunakan standar nasional. Namun, bila menggunakan standar ideal maka lebih dari separuh $(50,75 \%)$ yang harus dituntaskan.

\section{Simpulan dan Saran Simpulan}

Berdasarkan pada hasil dan bahasan di atas maka dapat disimpulkan bahwa menurut standar ideal, pemerataan pendidikan tinggi untuk Provinsi Bali belum bagus karena hanya mencapai $54,59 \%$ sehingga masih $45,41 \%$ yang harus ditangani sehingga tuntas. Namun, bila digunakan standar nasional maka pemerataan pendidikan tinggi telah tercapai $80,51 \%$.
Berdasarkan standar ideal, mutu pendidikan tinggi di Provinsi Bali ternyata masih menjadi masalah pokok dalam program pembangunan pendidikan. Kondisi ini nampak dari hasil analisis yang dicapai sebesar $43,92 \%$ sehingga masih $56,08 \%$ yang harus ditangani sehingga tuntas. Namun, bila digunakan standar nasional maka mutu Provinsi Bali mencapai lebih baik dari nasional, yaitu sebesar $100,11 \%$.

Jika digunakan standar ideal maka kinerja pendidikan tinggi di Provinsi Bali juga masih rendah dengan pencapaian $49,25 \%$ sehingga masih $50,75 \%$ yang harus ditangani agar menjadi tuntas. Namun, bila digunakan standar nasional maka kinerja pendidikan tinggi telah tercapai $88,21 \%$ sehingga hanya $11,79 \%$ yang perlu ditingkatkan.

\section{Saran}

Berdasarkan simpulan di atas maka agar pendidikan tinggi di Provinsi Bali meningkat dengan lebih baik dari segi pemerataan maupun mutu pendidikan tinggi maka beberapa hal perlu diperhatikan, yaitu: 1) partisipasi mahasiswa PT harus ditingkatkan agar APK sebesar 11,22\% meningkat menjadi minimal sama dengan nasional sebesar $12,39 \%$; 2) bila partisipasi mahasiswa PT dapat ditingkatkan maka R-M/Lbg juga akan meningkat; 3) rekruitmen dosen harus ditingkatkan baik dari segi jumlah maupun kualitas ijazah sehingga \%DL meningkat dan akibatnya akan meningkatkan mutu pendidikan; 4) oleh karena animo masuk ke PT sudah sangat besar, yaitu lebih dari $100 \%$ maka perlu dilakukan penerimaan mahasiswa lebih banyak jika dibandingkan dengan kondisi saat sekarang; dan 5) lama waktu lulusan harus dipercepat sehingga produktivitas akan meningkat dan memberi peluang yang lebih besar kepada mahasiswa baru yang masuk. Analisis profil pendidikan tinggi di Provinsi Bali ini dapat dijadikan model untuk melakukan analisis profil pendidikan tinggi di provinsi lainnya.

\section{Pustaka Acuan}

Biro Perencanaan. 2002. Data dan Indikator untuk Penyusunan Program Pembangunan Pendidikan. Jakarta: Sekretariat Jenderal.

Chamidi, S. 2006. Indikator Pendidikan dan Aplikasinya, Jurnal Pendidikan dan Kebudayaan, Januari 2006, Tahun ke-12, Nomor 058. 
Departemen Pendidikan Nasional. 2002. Pengkajian 13 Indikator Pendidikan. Jakarta: Pusat Data dan Informasi Pendidikan.

Departemen Pendidikan Nasional. 2003. Undang-Undang Republik Indonesia Nomor 20, Tahun 2003 tentang Sistem Pendidikan Nasional. Jakarta.

Departemen Pendidikan Nasional. 2005. Undang-Undang Nomor 14 Tahun 2005 tentang Guru dan Dosen. Jakarta.

Departemen Pendidikan Nasional. 2004a. Strategi Pendidikan Tinggi Jangka Panjang 2003-2010. Meningkatkan Peran Serta Masyarakat. Jakarta: Direktorat Jenderal Pendidikan Tinggi.

Departemen Pendidikan Nasional. 2004b. Strategi Pendidikan Tinggi Jangka Panjang 2003-2010. Mewujudkan Perguruan Tinggi Berkualitas. Jakarta: Direktorat Jenderal Pendidikan Tinggi.

Departemen Pendidikan Nasional. 2006a. Laporan Akuntabilitas Kinerja Depdiknas Tahun 2005-2006 (status 17 Oktober 2006) Buku I (Ringkasan Eksekutif), Jakarta.

Departemen Pendidikan Nasional. 2006b. Laporan Akuntabilitas Kinerja Depdiknas Tahun 2005-2006 (status 17 Oktober 2006) Buku II (Laporan Lengkap), Jakarta.

Departemen Pendidikan Nasional. 2007. Rencana Strategis Depdiknas Tahun 2005-2009, Jakarta: Pusat Informasi dan Humas.

Departemen Pendidikan Nasional. 2008. Pembangunan Pendidikan Nasional 2005-2008. Jakarta. http://id.wikipedia.org/wiki/Analisis diakses pada tanggal 22 Januari 2010.

http://www.baliprov.go.id/index.php?page=Struktur\%20Geologi diakses pada tanggal 25 Januari 2010.

Ida Kintamani. 2009a. Analisis profil Pendidikan Kabupaten Buleleng, Jurnal Pendidikan dan Kebudayaan, Januari 2009, Tahun ke-15, Nomor 1.

Ida Kintamani. 2009b. Pendayagunaan Data Pendidikan. Jakarta: Pusat Statistik Pendidikan.

Kementerian Pendididikan Nasional. 2010. Rencana Strategis Kementerian Pendidikan Nasional 20102014. Jakarta: Biro Perencanaan dan Kerjasama Luar Negeri, Sekretariat Jenderal.

Keputusan Menteri Pendidikan dan Kebudayaan Nomor 0259/U/1977 tentang Kordinasi Pengolahan Data di Departemen Pendidikan dan Kebudayaan.

Mahdiansyah. 2008. http://www.puslitjaknov.org/data/file/2008/makalah_ undangan/ Mahdiansyah Pemerataan\%20Perguruan\%20Tinggi.pdf diakses pada tanggal 20 Januari 2010.

Pusat Statistik Pendidikan. 2008a. Keberhasilan Program Pembangunan Pendidikan 2006/2007. Jakarta: Depdiknas.

Pusat Statistik Pendidikan. 2008b. Statistik dan Indikator Pendidikan Berwawasan Gender 2006/2007. Jakarta: Depdiknas.

Ramli, Murni. 2008 http://indosdm.com/menilai-mutu-pendidikan-di-jepang diakses pada tanggal 22 Januari 2010.

Tampubolon, D.P. 2009. 64 Tahun Merdeka, Mutu Pendidikan Nasional Masih Rendah. http:// hariansib.com/?p=88780 diakses pada tanggal 20 Januari 2010 . 